\title{
Saturação por bases no crescimento inicial e na produção de flavonóides totais da fava-d'anta
}

\author{
Cândido A da Costa*; Gisele A de Souza; Daniel S Alves; Cláudia B de Oliveira Araújo; Luiz A \\ Fernandes; Ernane R Martins; Regynaldo Arruda Sampaio; Paulo Sérgio do Nascimento Lopes \\ Universidade Federal de Minas Gerais/ICA, C. Postal 135, Bairro JK, 39404-006 Montes Claros-MG; E-mail: candido- \\ costa@nca.ufmg.br; *Autor Correspondente
}

\section{RESUMO}

Com o objetivo de estudar o efeito da calagem, mediante a elevação da saturação por bases, sobre o crescimento e a produção de flavonóides totais de fava-d'anta cultivada em um solo de Cerrado de Minas Gerais, foi conduzido um experimento no Instituto de Ciências Agrárias da Universidade Federal de Minas Gerais, no período de outubro/2003 a fevereiro/2004. O delineamento experimental utilizado foi inteiramente casualizado, sendo cinco valores de saturação por bases: 10 (saturação natural), 25; 40; 55 e 70\%, com seis repetições. Os resultados obtidos mostraram que o aumento da saturação por bases diminuiu o crescimento e não influenciou o teor de flavonóides totais da fava-d'anta.

Palavras-chave: Dimorphandra mollis, plantas medicinais, nutrição mineral.

\begin{abstract}
Base saturation affecting the initial growth and production of total flavonoids of Dimorphandra molli

With the purpose of studying the effect of levels of base saturation upon the growth and total flavonoids production of Dimorphandra mollis cultivated on a soil originally under Savana of Minas Gerais State, Brazil, an experiment was conducted at the Universidade Federal de Minas Gerais, between October/2003 and February/2004. The experiment followed a completely randomized design with five values of base saturation (V\%): 10 (natural saturation), 25; 40; 55 and $70 \%$, and six replicates. The increase of base saturation led to a decrease of Dimorphandra mollis growth, and did not influence the total flavonoids plant concentration.
\end{abstract}

Keywords: Dimorphandra mollis, medicinal plants, plant nutrition.

(Recebido para publicação em 21 de dezembro de 2005; aceito em 27 de fevereiro de 2007)

\begin{abstract}
$\mathrm{A}$ espécie Dimorphandra mollis, conhecida popularmente como favad'anta, pertence à família LeguminosaeCaesalpinoideae. É uma espécie arbórea nativa do Cerrado e com ampla distribuição nas áreas deste bioma com predominância de matas. Os frutos colhidos são destinados majoritariamente à indústria farmacêutica para extração principalmente do flavonóide rutina (Gomes \& Gomes, 2000), representando uma alternativa de renda para agricultores familiares do Norte de Minas Gerais.
\end{abstract}

Segundo Lorenzi (2002), a espécie apresenta ampla adaptabilidade a terrenos secos e de baixa fertilidade, podendo ser utilizada em programas de reflorestamento de áreas degradadas e de preservação permanente.

Na natureza, o alumínio é o terceiro metal mais abundante após o oxigênio e o silício, sendo encontrado sob diferentes formas, como aluminossilicatos insolúveis ou óxidos, sendo que as condições de acidez elevada dos solos do Cerrado favorecem a atividade do alumínio em solução, o qual se torna um cátion trocável (Ma et al., 2001).

As espécies vegetais apresentam variações quanto à tolerância ao alumínio trocável. Os efeitos tóxicos são observados primeiramente no sistema radicular, resultando em uma diminuição do alongamento celular, sendo que, em muitos casos a produção de biomassa radicular é mais afetada pelo alumínio tóxico do que a produção de biomassa da parte aérea (Machado, 2001).

Segundo Vázquez et al. (1999), o alumínio interfere na fixação do fósforo em formas menos disponíveis no solo ou na raiz da planta, diminui a respiração radicular e altera a absorção, transporte e uso de nutrientes e água pelas plantas, provocando alterações no metabolismo celular.

Os solos do Cerrado caracterizamse por apresentar $\mathrm{pH}$ baixo e elevada saturação por alumínio. Estes fatores são limitantes para o crescimento e desenvolvimento das espécies não adaptadas às condições de acidez do solo. Neste contexto, a calagem constitui em um método eficiente para a melhoria das características químicas do solo, neu- tralizando a fração tóxica do alumínio disponível (Lopes et al.,1991).

A função do alumínio e a sua interação com os nutrientes foram, por muitos anos, uma parte dos estudos de nutrição das plantas. Atualmente, esta área tem assumido grande importância na pesquisa agronômica e florestal, em virtude da crescente demanda por tecnologias para exploração de espécies florestais nativas. Entretanto, devido à variabilidade genética das florestas e à heterogeneidade dos solos das regiões tropicais, os dados disponíveis sobre a fisiologia destas espécies em relação às exigências nutricionais e sua capacidade de adaptação a condições ambientais distintas ainda são incipientes (Furtini Neto et al., 1999).

O objetivo deste trabalho foi determinar o efeito da calagem no crescimento inicial e o teor de flavonóides totais em mudas de fava-d'anta cultivadas em um LATOSSOLO VERMELHO distrófico e álico, mediante a avaliação de diferentes valores de saturação por bases. 


\section{MATERIAL E MÉTODOS}

O experimento foi conduzido em casa de vegetação, em Montes Claros, campus da UFMG, de outubro de 2003 a fevereiro de 2004. Utilizaram-se amostras coletadas na camada de 0 a 20 $\mathrm{cm}$ de profundidade de um LATOSSOLO VERMELHO distrófico e álico (Embrapa, 1999) sob vegetação de Cerrado, onde ocorre a fava d'anta, do município de Montes Claros (MG). As características físicas e químicas foram: $\mathrm{pH}$ em água 4,6; $\mathrm{P}=0,6 \mathrm{mg} \mathrm{dm}{ }^{-3}$; $\mathrm{Ca}=11,0 \mathrm{mmol}_{\mathrm{c}} \mathrm{dm}^{-3} ; \mathrm{Mg}=4,0 \mathrm{mmol}_{\mathrm{c}}$ $\mathrm{dm}^{-3} ; \mathrm{K}=1,0 \mathrm{mmol} \mathrm{dm}_{\mathrm{c}}^{-3} ; \mathrm{Al}=37 \mathrm{mmol}_{\mathrm{c}}$ $\mathrm{dm}^{-3} ; \mathrm{H}+\mathrm{Al}=140 \mathrm{mmol}_{\mathrm{c}} \mathrm{dm}^{-3} ; \mathrm{S}=16,0$ $\mathrm{mmol}_{\mathrm{c}} \mathrm{dm}^{-3} ; \mathrm{t}=53,0 ; \mathrm{m}=70 \% ; \mathrm{T}=$ $156 \mathrm{mmol} \mathrm{dm}^{-3} ; \mathrm{V}=10 \%$; matéria orgânica $=24 \mathrm{~g} \mathrm{~kg}^{-1}$; areia $=500 \mathrm{~g} \mathrm{~kg}^{-1}$; silte $=80 \mathrm{~g} \mathrm{~kg}^{-1}$ e argila $=420 \mathrm{~g} \mathrm{~kg}^{-1}$, determinados conforme Embrapa (1997).

O delineamento utilizado foi de blocos inteiramente casualizados, sendo cinco valores de saturação por bases (V\%): 10 (saturação natural), 25; 40; 55 e $70 \%$, e seis repetições. Foram cultivadas duas plantas por vaso plástico preenchido com $3 \mathrm{dm}^{3}$ de solo. As doses de calcário foram calculadas pelo método da saturação por bases conforme a análise química do solo utilizado no experimento e corresponderam a: $0 ; 1,17$; 2,34; 3,51 e 4,65 $\mathrm{g} \mathrm{dm}^{-3}$ de solo, respectivamente para os valores de saturação por bases de $10 ; 25 ; 40 ; 55$ e $70 \%$. Os solos foram incubados com as respectivas doses de corretivo por 45 dias com um calcário dolomítico calcinado, micro pulverizado, com $36 \%$ de $\mathrm{CaO}, 14 \%$ de $\mathrm{MgO}$ (PRTN igual a $100 \%), 0,02 \%$ de $\mathrm{Zn}, 0,01 \%$ de B, $0,03 \%$ de Fe, $0,03 \%$ de $\mathrm{Mg}$ e $0,00 \%$ de $\mathrm{Cu}$. Durante o período de incubação com o corretivo (45 dias) a umidade do solo foi mantida próxima a capacidade de campo.

As doses das fontes de macro e micronutrientes foram calculadas de modo a atender a adubação básica para cada tratamento, de acordo com Malavolta (1980), presentes nas seguintes concentrações: $100 \mathrm{mg} \mathrm{dm}^{-3}$ de $\mathrm{N} ; 300 \mathrm{mg}$ $\mathrm{dm}^{-3}$ de P; $100 \mathrm{mg} \mathrm{dm}^{-3}$ de $\mathrm{K} ; 200 \mathrm{mg}$ $\mathrm{dm}^{-3}$ de Ca; $60 \mathrm{mg} \mathrm{dm}^{-3}$ de $\mathrm{Mg} ; 40 \mathrm{mg}$ $\mathrm{dm}^{-3}$ de $\mathrm{S} ; 0,5 \mathrm{mg} \mathrm{dm}^{-3}$ de B; 1,5 mg dm
${ }^{3}$ de $\mathrm{Cu} ; 0,5 \mathrm{mg} \mathrm{dm}^{-3}$ de $\mathrm{Zn}$ utilizando como fontes os seguintes reagentes p.a: $\mathrm{NH}_{4} \mathrm{NO}_{3} ; \quad \mathrm{H}_{3} \mathrm{PO}_{4} ; \quad \mathrm{KH}_{2} \mathrm{PO}_{4}$; $\mathrm{MgSO}_{4} \cdot 7 \mathrm{H}_{2} \mathrm{O} ; \mathrm{CaSO}_{4} \cdot 2 \mathrm{H}_{2} \mathrm{O} ; \mathrm{Na}_{2} \mathrm{SO}_{4}$; $\mathrm{CuSO}_{4} .5 \mathrm{H}_{2} \mathrm{O} ; \mathrm{H}_{3} \mathrm{BO}_{3} ; \mathrm{ZnCl}_{2}$.

Para a formação das mudas foram selecionadas 300 sementes de favad'anta (Dimorphandra mollis Benth) provenientes de coletas realizadas em áreas de Cerrado do município de Montes Claros - MG.

As sementes foram submetidas ao tratamento com ácido sulfúrico concentrado para quebra de dormência durante uma hora, sendo lavadas posteriormente em água corrente durante $20 \mathrm{mi}$ nutos. A semeadura foi realizada em bandejas plásticas de $30 \times 50$ x $15 \mathrm{~cm}$, inicialmente desinfestadas com água sanitária, contendo uma camada de 15 $\mathrm{cm}$ de areia umedecida com água destilada, a qual foi posteriormente lavada e autoclavada por 20 minutos à pressão de $1 \mathrm{MPa}$. Depois de realizado o plantio, as bandejas foram cobertas com filme plástico transparente e levadas para $\mathrm{BOD}$ à temperatura de $28^{\circ} \mathrm{C}$ e fotoperíodo de 12 horas. O filme plástico foi retirado depois de iniciada a emergência e as plântulas permaneceram na BOD por 22 dias, sendo a seguir transferidas para os vasos em casa de vegetação. Durante o período experimental, a umidade do solo foi mantida próxima à capacidade de campo, pela reposição dos valores de água transpirados, estimados pela perda de peso diária de cada vaso.

Após 140 dias da semeadura, as plantas foram colhidas e o material vegetal foi seco a $65^{\circ} \mathrm{C}$ em estufa de circulação forçada de ar até peso constante, para determinação da matéria seca total da parte aérea e das raízes. Foram também determinados o diâmetro do caule à altura do colo, altura de plantas e o teor de flavonóides totais nas folhas, sendo este obtido segundo metodologia adaptada de Santos \& Blatt (1998). Os resultados obtidos foram submetidos à análise de variância e os tratamentos comparados por análise de regressão.

\section{RESULTADOS E DISCUSSÃO}

Para a produção de matéria seca da parte aérea e raiz e altura de plantas fo- ram observadas diferenças significativas entre os tratamentos $(\mathrm{P}<0,01)$. Após a reação do calcário, as saturações por bases determinadas foram $10 ; 19 ; 28$; 42 e $58 \%$, respectivamente para os tratamentos saturação natural, 25; 40; 55 e $70 \%$.

Tanto a produção de matéria seca da parte aérea (Figura 1a) quanto de raiz (Figura 1b) apresentaram decréscimos lineares com o aumento da saturação por bases do solo e conseqüente diminuição da toxidez por alumínio. A produção de matéria seca da parte aérea e da raiz na última saturação testada $(70 \%)$ foi $53,5 \%$ e $56 \%$, sendo estes valores menores que na saturação natural (10\%), respectivamente. Dessa forma, pode se inferir que em condições naturais de acidez do solo de Cerrado, onde ocorre a fava d'anta, há um melhor crescimento desta espécie e que, para a produção de mudas não é recomendada a adição de calcário ao substrato.

Resultados semelhantes foram observados para o ipê-mirim (Tecoma stans) crescido em solução nutritiva com uma concentração elevada de alumínio (10 mg/l) (Machado, 2001). Também Junior et al. (2004) verificaram redução da biomassa fresca e seca total de plantas de arnica (Lychnofora pinaster), quando foi realizada a correção do solo com calcário. Vale et al. (1996), estudando o efeito da acidez do solo em quinze espécies florestais, algodão e milho, verificaram comportamento distinto entre as espécies florestais, enquanto o algodão e o milho foram sensíveis à acidez do solo.

Ratter et al. (1978) estudando a ocorrência de espécies vegetais nos cerrados do Brasil Central, observaram que algumas ocorrem somente em solos ácidos, outras são restritas aos solos calcários e outras são indiferentes. Segundo Haridasan (2000), raramente a vegetação do Cerrado ocorre em solos com altos teores de cálcio e magnésio, sendo que algumas espécies têm um melhor desenvolvimento em solos com teores mais elevados de alumínio trocável.

No presente estudo, mesmo no tratamento sem aplicação de calcário, o cálcio e o magnésio não foram limitantes, uma vez que foram aplica- 
dos na adubação básica, na forma de sulfato de cálcio e sulfato de magnésio, respectivamente. Como em condições naturais a fava d'anta ocorre em solos ácidos e com baixa disponibilidade de cálcio e magnésio, pode se inferir que esta espécie é adaptada aos baixos teores desses nutrientes. Uma explicação é a elevada capacidade de troca de cátions das raízes das leguminosas que confere maior absorção de $\mathrm{Ca}$ e $\mathrm{Mg}$ dos solos (Rosolem, 1989). No caso do magnésio, segundo Malavolta (1980), pode ainda ocorrer que o conteúdo deste elemento na semente seja suficiente para garantir uma nutrição adequada para o desenvolvimento de algumas espécies.

Além do maior crescimento da fava d'anta nas condições naturais de acidez do solo em estudo, verificou-se a presença de nódulos nas raízes, indicando que esta espécie faz simbiose com bactérias fixadoras de nitrogênio, mostrando potencial para sua utilização em programas de recuperação de áreas degradadas.

No caso do fósforo aplicado na adubação básica, as condições naturais de acidez do solo sob Cerrado em estudo podem ter diminuído a disponibilidade desse elemento. No entanto, como não foram observados sintomas visuais de deficiência de fósforo nas plantas, a fava-d'anta pode ter desenvolvido mecanismos de adaptação a esta condição, tais como maior crescimento do sistema radicular, maior número de raízes finas, associação com fungos micorrizicos, entre outros. Mendes et al. (2005), verificaram maior produção de biomassa de mudas de fava d'anta crescida em baixos níveis de fósforo em solução nutritiva. Segundo os autores, esse comportamento evidencia a adaptação da espécie aos solos sob Cerrado, com baixa disponibilidade de fósforo.

Em relação à altura das plantas, observou-se um comportamento quadrático (Figura 1c) e de acordo com a equação de regressão ajustada, a máxima altura de plantas $(26,30 \mathrm{~cm})$ foi atingida quando a saturação por bases no solo foi de $32 \%$. Já para o diâmetro do caule não foram verificadas diferenças significativas entre os tratamentos, sendo o diâmetro médio das plantas de fava-d'anta, nesta fase de crescimento, de $3,43 \mathrm{~mm}$.
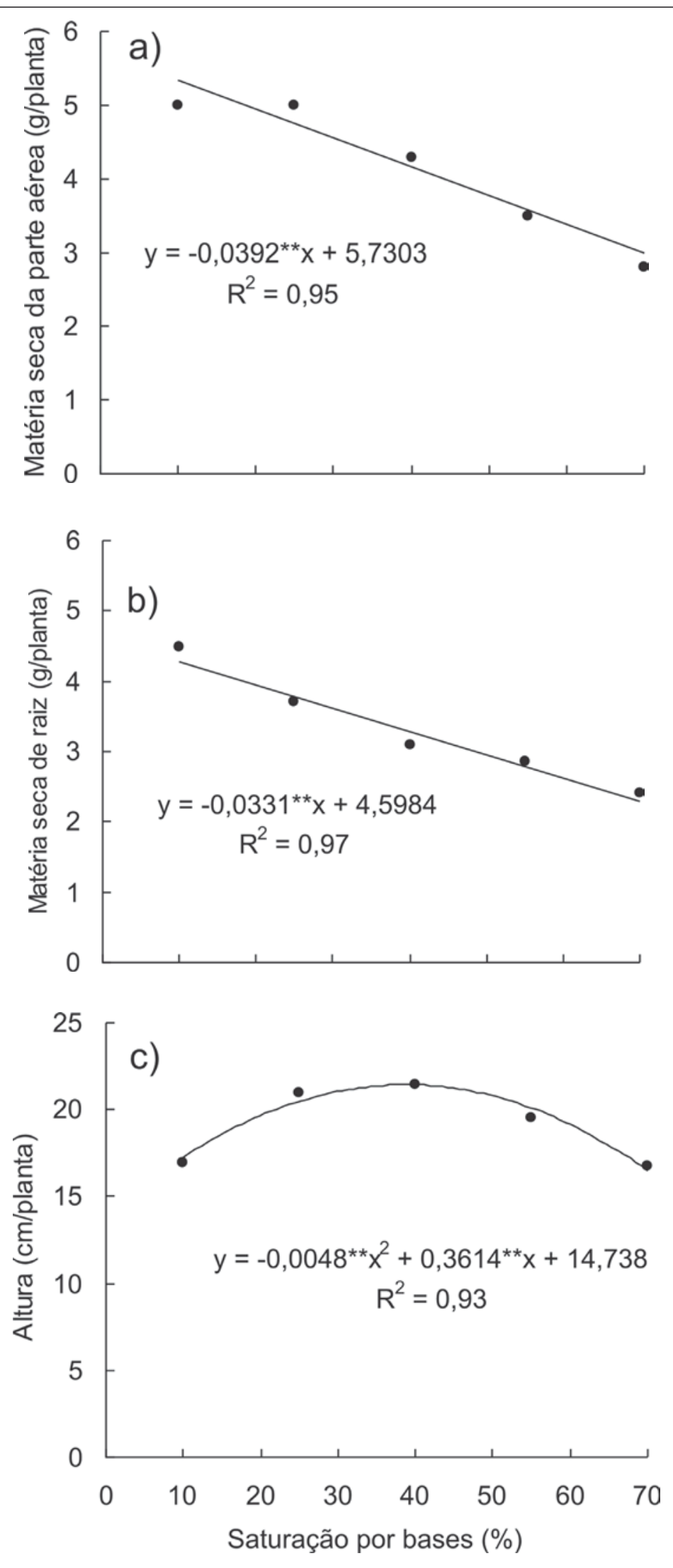

Figura 1. Matéria seca da parte aérea (a) e de raiz (b) e altura (c) das plantas de fava-d'anta (Dimorphandra mollis Benth.) em função dos valores de saturação por bases do solo. (Dry matter of aerial part (a) and of roots (b) and height (c) of fava-d'anta plants, as a function of soil bases saturation). Montes claros, UFMG, 2005. 
Quanto ao teor de flavonóides totais, não foi observada diferença significativa entre os tratamentos, sendo o valor médio de $0,36 \%$ em análises realizadas nos folíolos. Em seus estudos com camomila (Chamomilla recutita), Wagner \& Bladt (1996) e Mapeli et al. (2005), verificaram que o teor de óleo essencial dos capítulos florais não variou entre os tratamentos com ou sem fertilização. Por outro lado, Mendes et al. (2005) observaram, em solução nutritiva, que baixos níveis de fósforo no meio, sem apresentação de sintomas visuais de deficiência pela planta de fava-d'anta, aumentam os teores de flavonóides totais.

Com base nos resultados deste trabalho, pode-se concluir que a calagem reduziu o crescimento da parte aérea e radicular e não afetou o teor foliar de flavonóides totais. Portanto, a adição de calcário ao substrato pode ser omitida na produção de mudas de fava d'anta.

\section{AGRADECIMENTOS}

À FAPEMIG pelo apoio.

\section{REFERÊNCIAS}

EMBRAPA. 1997. Serviço Nacional de Levantamento e Conservação de Solo. Manual de métodos de análise de solo. Rio de Janeiro: Ministério da agricultura. 212p.
FURTINI NETO AE; RESENDE AV; VALE FR; VALE FAQUIN V; FERNANDES LA. 1999. Acidez do solo, crescimento e nutrição mineral de algumas espécies arbóreas na fase de muda. Revista Cerne 5: 1-12.

GOMESLJ; GOMES MAO. 2000. O extrativismo e biodiversidade: a caso da fava- d'anta. $\mathrm{Ci}$ ência Hoje 27: 66-69.

HARIDASAN M. 2000. Nutrição mineral de plantas nativas do cerrado. Revista Brasileira de Fisiologia vegetal 12: 54-64.

JÚNIOR ACO; FAQUIN V; PINTO JEBP; SOBRINHO RRL; BERTOLUCCI SKV; TEIXEIRA NR. 2004. Teor e rendimento de óleo essencial de mudas de arnica, em função de calagem e adubação. Mato Grosso do Sul, v. 22, n. 2, 2004. Suplemento. CD-ROM. Trabalho apresentado no $44^{\circ}$ Congresso Brasileiro de Olericultura.

LOPES AS; SILVA MC; GUILHERME LRG. 1991. Boletim Técnico $n^{\circ}$ 1: Acidez do solo e calagem. São Paulo: Associação Nacional para Difusão de Adubos. 14p.

LORENZI H. 2002. Árvores brasileiras: manual de identificação e cultivo de plantas arbóreas nativas do Brasil. 4.ed. São Paulo: Nova Odessa. 352p.

MA JF; RYAN PR; DELHAIZE E. 2001. Aluminum tolerance in plants and the complexing role of organic acids. Trends in Plant Science 6: 273-279.

MACHADO RMA; MOTA EO; FURTINI NETO AE; FILHO ND. 2001. Comportamento diferencial das espécies florestais cássia-verrugosa (Senna multijuga (L.C. RICH.) I. \& B.) e ipêmirim (Tecoma stans H.B.K.) na presença de alumínio. Ciência Agrotecnológica 25: 11611168 .
MALAVOLTA E. 1980. Elementos de Nutrição Mineral de Plantas. São Paulo: Agronômica Ceres. $251 \mathrm{p}$.

MAPELI NC; VIEIRA MC; HEREDIA ZNA; SIQUEIRA JM. 2005. Produção de biomassa e de óleo essencial dos capítulos florais de camomila em função de nitrogênio e fósforo. Horticultura Brasileira 23: 32-37.

MENDES ADR; MARTINS ER; FERNANDES LA; MARQUES CCL. 2005. Produção de biomassa e de flavonóides totais por fava-d'anta (Dimorphandra mollis Benth) sob diferentes níveis de fósforo em solução nutritiva. Revista Brasileira de Plantas Medicinais 7: 7-11.

RATTER JA; RICHARDS PW; ARGENT G; GIFFORD DR. 1978. Observations on the forest of some mesotrophic soils in central Brazil. Revista Brasileira de Botânica 1: 47-58.

ROSOLEM CA. 1989. Interpretação de análise química de solo e planta para fins de adubação. Botucatu: Fundação de Estudos e Pesquisas Agrícolas e Florestais. p.97-128.

SANTOS MD; BLATT CTT. 1998. Teor de flavonóides e fenóis totais em folhas de Pyrostegia venusta Miers. de mata e de Cerrado. Revista Brasileira de Botânica 21: 1-9.

VALE FR; FURTINI NETO AE; RENÓ NB; FERNANDES LA; RESENDE AV. 1996. Crescimento radicular de espécies florestais em solo ácido. Pesquisas Agropecuária Brasileira 31: 609-616.

VÁZQUEZ MD; POSCHENRIEDER C; CORRALES I; BARCELÓ J. 1999. Change in apoplastic Al during the initial growth response to $\mathrm{Al}$ by roots of a resistant maizes variety. Plant physiology 119: 435-444.

WAGNER H; BLADT S. 1996. Plant drug analysis - a thin layer chromatography atlas. 2.ed. Berlin: Springer. 384 p. 